\title{
Significance of cyanobacterial diversity in different ecological conditions of Meghalaya, India
}

\author{
Mayashree B Syiem*, B Bashisha Nongbri, A Pinokiyo, Amrita Bhattacharjee, Natasha A \\ Nongrum and Luxemburgh Hynniewta
}

Department of Biochemistry, North Eastern Hill University, Shillong-793022 (Meghalaya), INDIA

*Corresponding author. E-mail: mayashreesyiem@yahoo.co.in

\begin{abstract}
The present study deals with preliminary investigation of cyanobacterial diversity in Meghalaya. A total of 75 samples were collected from 10 different ecosystems and analyzed. 65 strains of cyanobacteria isolated under 11 genera include Nostoc, Anabaena, Calothrix, Cylindrospermum, Gleocapsa, Fischerella, Plectonema, Tolypothrix, Stigonema, Loriella and Westiellopsis. Nostoc was most abundant. Diversity analysis indicated maximum Shannon's diversity index $(\mathrm{H})$ in Mawlai. Highest Simpson's diversity index was seen in Sung Valley (0.75). Both Shannon's and Simpson's diversity indices were lowest in Mairang. Richness was highest in Sung valley and Syntuksiar with both the sites supporting 17 strains each. Although, highest diversity was recorded from Mawlai, richness recorded at this site was only 11 strains thereby indicating richness need not be a function of diversity in this region. This study revealed the cyanobacterial strains, which can withstand acidic $\mathrm{pH}$ and prevail in the region. A study on colonization also identified some potential biofertilizer strains from the region such as Nostoc punctiforme, Nostoc muscurum and Anabaena azollae that could be effective in acidic crop fields.
\end{abstract}

Keywords: Northeast India, Biodiversity hot spots, Cyanobacterial diversity, Shannon's index and Simpson's diversity index

\section{INTRODUCTION}

Cyanobacteria are a group of gram negative, morphologically diverse, aerobic phototrophs whose distribution is ubiquitous in nature and are found everywhere including places with extreme climatic conditions such as in Antarctica, in hot springs (Whitton and Potts, 2000) and even in oxic and anoxic environments (Thajuddin and Subramanian, 2005). They flourish in places with nitrogen deficient environment. They are important as they contribute towards carbon and nitrogen economy of different ecological habitats and can grow in purely inorganic medium using light as energy and $\mathrm{CO}_{2}$ and $\mathrm{N}_{2}$ as sole carbon and nitrogen sources respectively (Wyatt and Silvey, 1969). The role of nitrogen fixing cyanobacteria in enhancing soil fertility has been long known and is well documented (Singh, 1961; Venkataraman, 1981). Cyanobacteria contribute to overall soil health not only by its ability to perform biological nitrogen fixation but also because of its ability to produce polysaccharides and other bioactive compounds which have growth stimulating effect on plants, as well as important in maintaining soil quality and preventing erosion. However, in nature cyanobacteria are constantly challenged by different factors and stresses including fluctuations in temperature, $\mathrm{pH}$, moisture content (droughts and floods), salinity and so forth. These factors influence distribution and diversity of cyanobacteria in a region. Among these, $\mathrm{pH}$ is an important determinant as cyanobacteria are known to prefer neutral to alkaline pH for their optimum growth (Singh, 1961; Kaushik, 1994). In recent times, studies on cyanobacterial diversity has received due attention (Thajuddin and Subramanian, 2005; Prasanna et al. 2009). However, work and publications on this group of microorganisms from Northeast India is sporadic despite the fact that this region falls within Indo-Malayan biodiversity hot spot (Myres et al. 2000). Meghalaya is one of the 8 states of the northeastern India, lying between $25^{\circ} 5^{\prime} \mathrm{N}$ and $26^{\circ} 10^{\prime} \mathrm{N}$ latitudes and $89^{\circ} 47^{\prime} \mathrm{E}$ and $92^{\circ} 47^{\prime} \mathrm{E}$ longitudes covering an area of 22,429 sq. km. Physio-geographically the region consists of hilly terrains. Diverse terrestrial and aquatic ecosystems including extreme ones (hot springs) could be encountered within the state. The climate is moderate but humid. It also receives the highest rainfall in the world with average annual rainfall as high as $1200 \mathrm{~mm}$ making Meghalaya the wettest state of India. The natural ecosystems such as soil, freshwater bodies-streams, ponds, lakes, rivers, hot springs, and trees within extensive forest areas provide excellent habitats and favourable environments for the luxuriant and diverse growth of cyanobacteria. However, the region also exhibit neutral to acidic range of soil and water $\mathrm{pH}$. It is the 
Table 1. Cyanobacterial Collection sites

\begin{tabular}{|c|c|c|c|c|}
\hline \multirow[t]{2}{*}{ Locality } & \multicolumn{2}{|c|}{ Location } & \multirow{2}{*}{$\begin{array}{l}\text { No. of } \\
\text { samples } \\
\end{array}$} & \multirow[t]{2}{*}{ Type of ecosystems } \\
\hline & Longitude & Latitude & & \\
\hline Syntu Ksiar & $92^{\circ} 12^{\prime} 39^{\prime \prime} \mathrm{E}$, & $25^{\circ} 25^{\prime} 59^{\prime \prime} \mathrm{N}$ & 8 & Rice field, soil, water \\
\hline Mawphlang & 91'45'37'”E & $25^{\circ} 27^{\prime} 02^{\prime \prime} \mathrm{N}$ & 7 & Soil, water, tree barks \\
\hline Sung Valley & $92^{\circ} 06^{\prime} 15^{\prime \prime} \mathrm{E}$ & $25^{\circ} 30^{\prime} 09^{\prime \prime} \mathrm{N}$ & 8 & Rice field, soil, water \\
\hline Nongstoin & $91^{\circ} 16^{\prime} 14^{\prime \prime} \mathrm{E}$ & $25^{\circ} 30^{\prime} 34^{\prime \prime} \mathrm{N}$ & 8 & Rice field, soil, water \\
\hline Mairang & $91^{\circ} 38^{\prime} 26^{\prime \prime} \mathrm{E}$ & $25^{\circ} 33^{\prime} 55^{\prime \prime} \mathrm{N}$ & 7 & Soil, water, tree barks \\
\hline Mawlai & $91^{\circ} 52^{\prime} 11^{\prime \prime} \mathrm{E}$ & $25^{\circ} 35^{\prime} 42^{\prime \prime} \mathrm{N}$ & 8 & $\begin{array}{l}\text { Tree barks, rice fields, } \\
\text { soil, water }\end{array}$ \\
\hline Mawroh & $91^{\circ} 53^{\prime} 54^{\prime \prime} \mathrm{E}$ & $25^{\circ} 35^{\prime} 54^{\prime \prime} \mathrm{N}$ & 7 & $\begin{array}{l}\text { Rice field, soil, water, } \\
\text { tree barks }\end{array}$ \\
\hline Umkhen & $92^{\circ} 07^{\prime} 51^{\prime \prime} \mathrm{E}$ & $25^{\circ} 36^{\prime} 18^{\prime \prime} \mathrm{N}$ & 7 & Soil, water, tree barks \\
\hline Umiam & $91^{\circ} 54^{\prime} 11^{\prime \prime} \mathrm{E}$ & $25^{\circ} 39^{\prime} 59^{\prime \prime} \mathrm{N}$ & 8 & $\begin{array}{l}\text { Tree barks, soil, water, } \\
\text { rice field }\end{array}$ \\
\hline Umsning & 91'54'10’'Е & $25^{\circ} 42^{\prime} 59^{\prime \prime} \mathrm{N}$ & 7 & $\begin{array}{l}\text { Stagnant pond, rice fields, } \\
\text { soil }\end{array}$ \\
\hline
\end{tabular}

Total number of samples collected $=75$

interplay among such favourable and adverse conditions that has resulted in shaping the distinct biodiversity of the region. Keeping these facts in view, we have collected samples from diverse ecosystems to assess cyanobacterial diversity of the state. Since, cyanobacteria have immense potential for varied biotechnological applications, the present investigation was undertaken

Table 2. Distribution of strains within genera in different localities.

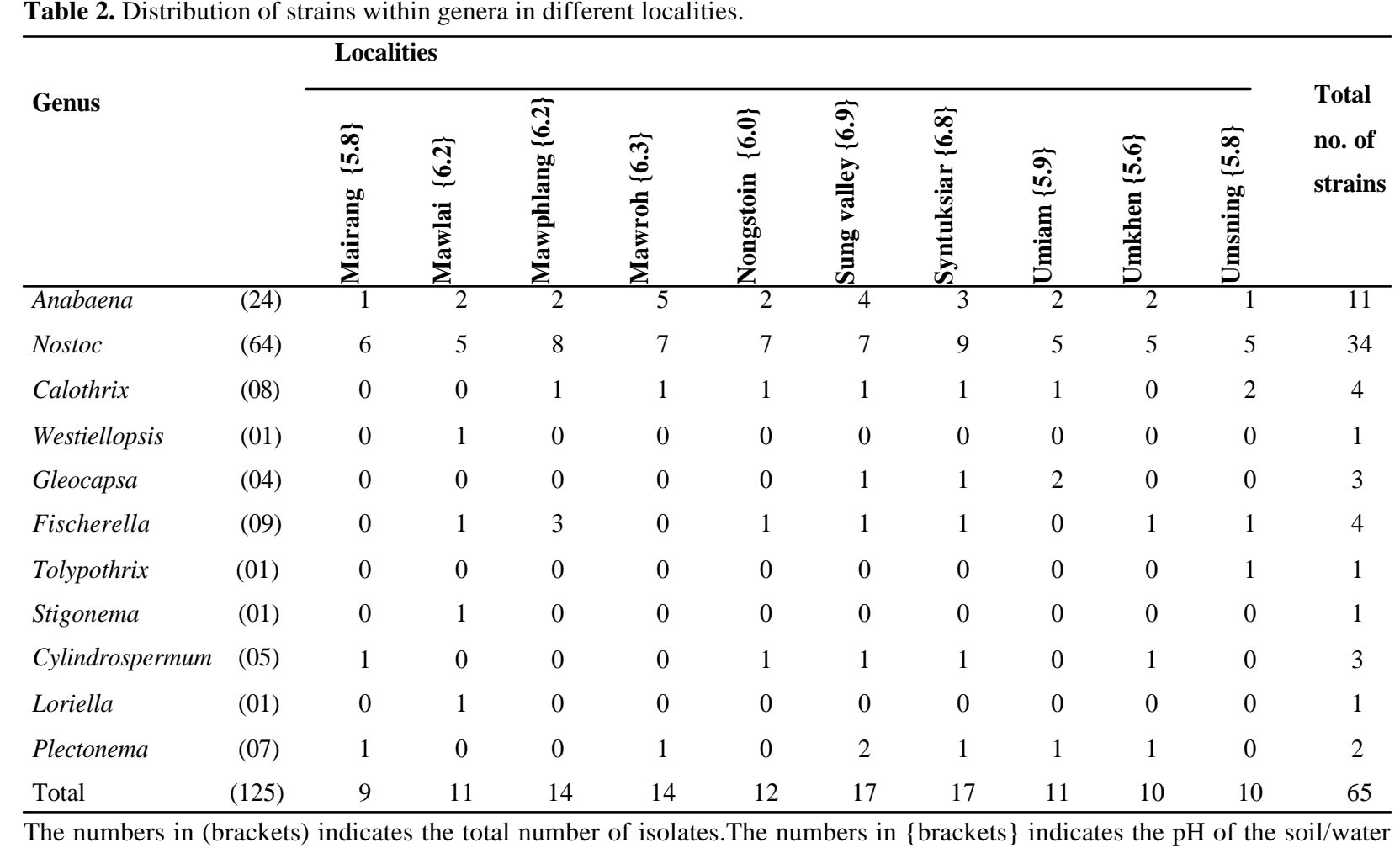

The numbers in (brackets) indicates the total number of isolates. The numbers in $\{$ brackets $\}$ indicates the $\mathrm{pH}$ of the soil/water sample collected. to get a database of available cyanobacteria (blue green algae) under diverse ecological conditions in different districts of Meghalaya.

\section{MATERIALS AND METHODS}

Study Area: Four districts of Meghalaya namely East Khasi Hills, West Khasi Hills, Jaintia Hills and Ri Bhoi 
Table 3. Generic diversity indices and dominance for different localities.

\begin{tabular}{|c|c|c|c|c|c|c|c|c|c|c|c|}
\hline 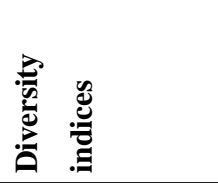 & 尝 & 莃 & 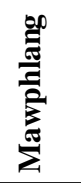 & 胥 & 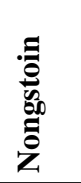 & 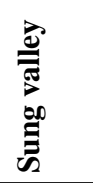 & 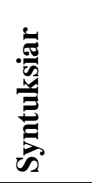 & 芯 & 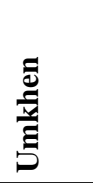 & : & $\stackrel{\stackrel{n}{n}}{=}$ \\
\hline $\begin{array}{l}\text { Shannon- } \\
\text { Weiner's } \\
\text { Diversity Index }\end{array}$ & 1.002 & 1.976 & 1.11 & 1.09 & 1.23 & 1.624 & 1.476 & 1.414 & 1.359 & 1.359 & 1.63 \\
\hline $\begin{array}{l}\text { Simpson's } \\
\text { Diversity index }\end{array}$ & 0.52 & 0.71 & 0.60 & 0.61 & 0.61 & 0.75 & 0.67 & 0.71 & 0.68 & 0.68 & 0.68 \\
\hline $\begin{array}{l}\text { Simpson's } \\
\text { Dominance }\end{array}$ & 0.48 & 0.29 & 0.40 & 0.39 & 0.39 & 0.25 & 0.33 & 0.29 & 0.32 & 0.32 & 0.32 \\
\hline $\begin{array}{l}\text { Cyanobacterial } \\
\text { richness }\end{array}$ & 9 & 11 & 14 & 14 & 12 & 17 & 17 & 11 & 10 & 10 & 65 \\
\hline
\end{tabular}

were chosen for the study. Samples were collected randomly from different types of ecosystems: terrestrial ground, terrestrial epiphyte and aquatic (Table.1). The sites were selected carefully to include diverse environments in terms of altitude, $\mathrm{pH}$, and temperature, moist or water logged conditions as well as hilly or low lying terrain.

Aquatic samples were collected in specimen collection tubes. Soil samples were collected by scraping the surface of the soil and epiphytic samples were collected by scraping the upper surface of barks of different trees. $\mathrm{pH}$ of the collected samples was analysed using the method described by Black in 1992.

Isolation, purification and cultivation of cyanobacteria: Isolation and purification of cyanobacterial strains were carried out as described by Packer and Glazer (1988). The pure strains were maintained in BG- $11_{0}$ media (Rippka et al. 1979).

Growth, heterocyst frequency and nitrogenase activities: Growth was measured as increase in chlorophyll $a$ content (McKinney, 1941). Heterocyst frequency was calculated as percentage of total cells by using an Olympus BX 51 light microscope (Wolk, 1965). The results are mean of three independent observations. Nitrogenase activity was estimated in vivo by gas chromatography using the acetylene reduction assay. $5 \mathrm{ml}$ liquid culture was placed in a $15 \mathrm{ml}$ serum vial and $1 \mathrm{ml}$ air in the tube was replaced by $1 \mathrm{ml}$ of pure acetylene. These vials were incubated for $1 \mathrm{hr}$ at $25 \pm 1^{\circ} \mathrm{C}$ with constant shaking. The ethylene produced in each vial was determined using a Tracor 540 GC with a Porapak ' $\mathrm{T}$ ' column and a flame ionization detector (Stewart et al. 1967).

Immobilization for preservation: The purified strains were preserved by immobilization in calcium alginate beads (Musgrave et al. 1982). The viability of the strains under preservation was established by regenerating the isolates periodically in liquid media. Regeneration of the immobilized filaments was confirmed visually. Nitrogenase enzyme was assayed in the regenerated cultures to ascertain no loss of this crucial character in the isolates due to preservation.

Richness and diversity of cyanobacteria: Genera were

Table 4. Colonization study: Associated chlorophyll a content and comparative nitrogenase activities of associated Nostoc isolates to their free-living counterparts.

\begin{tabular}{|c|c|c|c|c|}
\hline \multirow[t]{2}{*}{ Sl. No. } & \multirow{2}{*}{$\begin{array}{c}\text { Isolate } \\
\text { no. }\end{array}$} & \multirow{2}{*}{$\begin{array}{l}\text { Associative chlorophyll } \\
a\left(\mu \mathrm{g} \mathrm{g}^{-1} \text { root dry wt) }\right.\end{array}$} & \multicolumn{2}{|c|}{ Nitrogenase activity } \\
\hline & & & $\begin{array}{c}\text { Free-living isolates } \\
\left(\text { nmol } \mathrm{C}_{2} \mathrm{H}_{4} \text { produced } \mu \mathrm{g}^{-1}\right. \\
\left.\operatorname{chl} a \mathbf{h}^{-1}\right)\end{array}$ & $\begin{array}{c}\text { Associated isolates } \\
\text { (nmol } \mathrm{C}_{2} \mathrm{H}_{4} \text { produced } \mu \mathrm{g}^{-1} \\
\text { chl } a \mathrm{~h}^{-1} \text { ) }\end{array}$ \\
\hline 1 & 27 & 987 & 7.92 & 12.56 \\
\hline 2 & 12 & 782 & 7.20 & 9.69 \\
\hline 3 & 28 & 767 & 6.88 & 9.41 \\
\hline 4 & 29 & 532 & 6.53 & 7.31 \\
\hline 5 & 18 & 519 & 6.41 & 7.22 \\
\hline 6 & 4 & 411 & 6.35 & 6.65 \\
\hline 7 & 7 & 368 & 6.32 & 6.67 \\
\hline 8 & 8 & 362 & 6.21 & 6.49 \\
\hline 9 & 20 & 330 & 5.90 & 6.11 \\
\hline
\end{tabular}


identified under microscope with the help of Desikachary (1959) and strains were sorted out on the basis of morphology. Total number of strains under each genus was counted for estimating diversity and richness of cyanobacteria in study area. Generic diversity was estimated by Shannon-Weiner Index (H) (Shannon and Weaver, 1949) and Simpson's diversity (1-D) (Simpson 1949) using the following formulae:

Shannon-Weiner Index, $\quad \mathrm{H}=-$ Spi ln pi

Simpson's Dominance, $\quad \mathrm{D}=\mathrm{S}(\mathrm{pi})^{2}$

Simpson's Diversity Index, $1-\mathrm{D}=1-\mathrm{S}(\mathrm{pi})^{2}$

where $\mathrm{pi}=$ Total number of strains of genus $\mathrm{i} /$ total number of all strains.

Rice-cyanobacterial colonization study: Rice plants (Oriza sativa L.) local variety 'Synteng' was collected from ICAR-NEH Region Complex (Umiam, Shillong, India). The seeds were washed and surface sterilized using $1 \%$ sodium hypochlorite solution for 5 minutes. They were then rinsed thoroughly with sterile water and grown on autoclaved perlite in glass beakers. These beakers were irrigated with 10 times diluted sterile BG- $11_{0}$ media supplemented with $2 \mathrm{mM} \mathrm{NaNO}_{3}$ from time to time. 10 days old rice seedlings were transferred to $15 \mathrm{ml}$ capacity tubes after washing them with distilled water. $5 \mathrm{ml} \mathrm{BG-11}$ 。 medium was poured into the tubes carefully dipping the roots in the medium. Nostoc filaments from exponentially growing cultures were introduced into the tubes (initial chlorophyll $a$ content of the inoculums was kept at $1 \mu \mathrm{g}$ $\mathrm{ml}^{-1}$ per tube). Association was confirmed under microscope as well as by estimating chlorophyll $a$ concentration in the rice roots after removing loosely associated filaments using a sonic bath.

\section{RESULTS AND DISCUSSION}

Role of cyanobacteria in improving soil health and fertility is well known. To exploit the full potential of cyanobacteria in management of soil quality and fertility coordinated efforts between laboratory and field level research is needed. Region-based specific cyanobacterial isolates could be more effective in such applications as they are pre-acclimatised to the existing environmental conditions. Hence a region-specific biodiversity study is important for deriving optimum benefits from indigenous strains. Knowledge of cyanobacterial diversity of a region may help in selecting appropriate cyanobacterial inocula to be applied as biofertilizer consortia in crop fields as well as help in finding strains with other biotechnological potentials. Earlier we have reported one such Anabaena isolate from an acidic rice field in Cherrapunjee, Meghalaya that can grow at high cadmium concentration and is efficient in removing cadmium (Syiem et al. 2009). Thus, this investigation of cyanobacterial diversity is ecologically significant as it enumerates diversity, abundance, dominance and richness of various cyanobacteria in a region with primarily acidic soil and water $\mathrm{pH}$. Such findings are important as they pinpoint biological strains that can be used to improve quality and enhance fertility of acidic soil.

Seventy five samples were collected from ten independent sites located in different districts of the state (Table 1). Almost all collection sites recorded acidic $\mathrm{pH}$ (6-7 in the $\mathrm{pH}$ scale). Of the total 65 strains isolated (Table 2), 92\% were heterocystous cyanobacteria. Of which $51 \%$ alone was Nostoc and $16 \%$ was Anabaena. Predominance of the genera Nostoc in all collection sites irrespective of $\mathrm{pH}$ and other influencing factors including terrain, water logging, temperature, altitude and moisture content indicates towards their versatility, competiveness and ability to occupy diverse ecological niches. Growth was estimated in all 34 Nostoc isolates at $\mathrm{pH} 6.0$ and at $\mathrm{pH} 7.5$. Low growth of all isolates in $\mathrm{pH} 6.0$ indicated compromised growth in acidic field conditions. Heterocyst frequency of the Nostoc strains at pH 6.0 was found to be within the range of $4.2-8.3 \%$ (Fig. 1a). Corresponding nitrogenase activity ranged from 3.9-7.9 nmol $\mathrm{C}_{2} \mathrm{H}_{4}$ produced $\mu \mathrm{g}^{-1}$ chl $a \mathrm{~h}^{-1}$ (Fig. 1b). When compared, the correlation between increased heterocyst frequency and nitrogenase activity in the Nostoc isolates was evident with isolate no. 27 showing highest heterocyst frequency and nitrogenase activity followed by isolate nos. 12, 28 and 29 .

Syntuksiar and Sung valley in Meghalaya primarily constitute widespread rice cultivation areas in the state. Statistical analysis revealed high richness and high Shannon's diversity indices in Syntuksiar and Sung valley (Table 3). Such values suggest that rice fields provide ideal environments for cyanobacterial diversity and growth despite the frequent use of agrochemicals in rice cultivation in order to enhance yield. In our study richness of cyanobacterial genera was found to vary with respect to $\mathrm{pH}$ of a particular collection site (Table 2). Although all sites recorded acidic $\mathrm{pH}$, greater diversity and larger number of isolates were gathered from places that showed $\mathrm{pH}$ close to neutral. Prevalence of Nostoc and Anabaena in all sites indicated their resilience and high adaptability in varied types of ecosystems. However, Westiellopsis, Tolypothrix, Stigonema and Loriella sps. of cyanobacteria were not common in the state as only one isolate of each was found in the total collection.

In diversity study, richness relates to abundance of different genera/species of a group of organisms in an area and stands as a measure of number of different kinds of genera/species in that particular area. Low generic richness was seen in Mairang, Mawphlang and Mawroh areas. On the other hand, high generic richness was recorded in Syntuksiar and Sung valley. That diversity of an area strongly depends on $\mathrm{pH}$ and on interplay of various environmental factors is evident from this study 


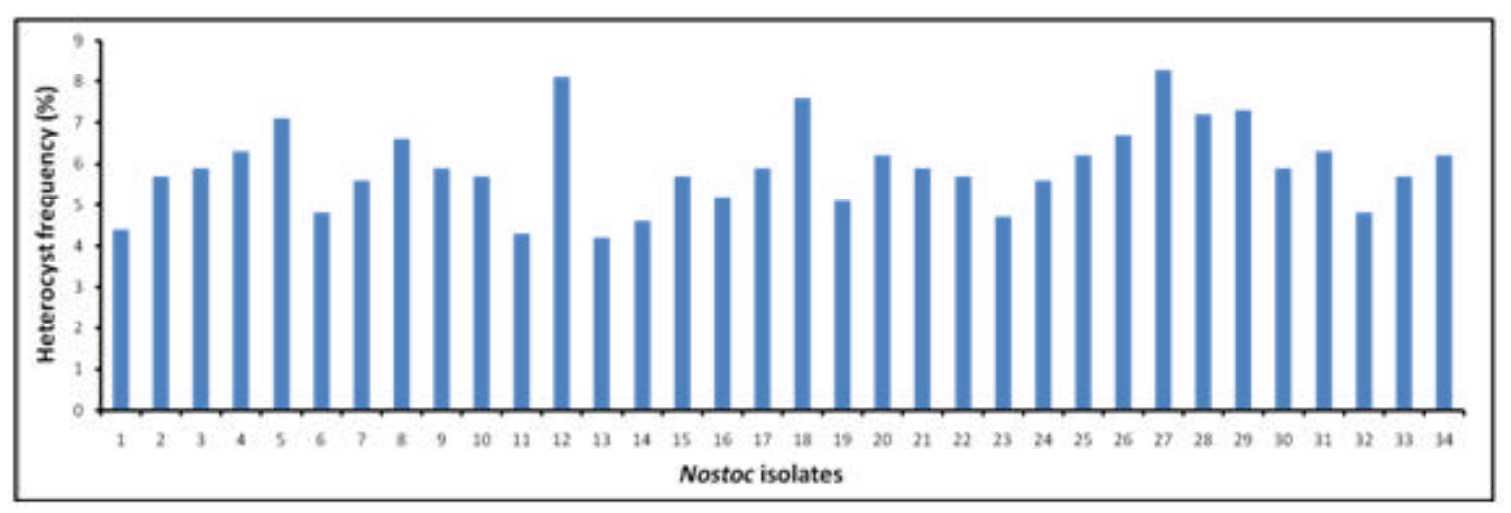

Fig. 1. (a) Heterocyst frequency of Nostoc isolates (data is mean of three independent experiments).

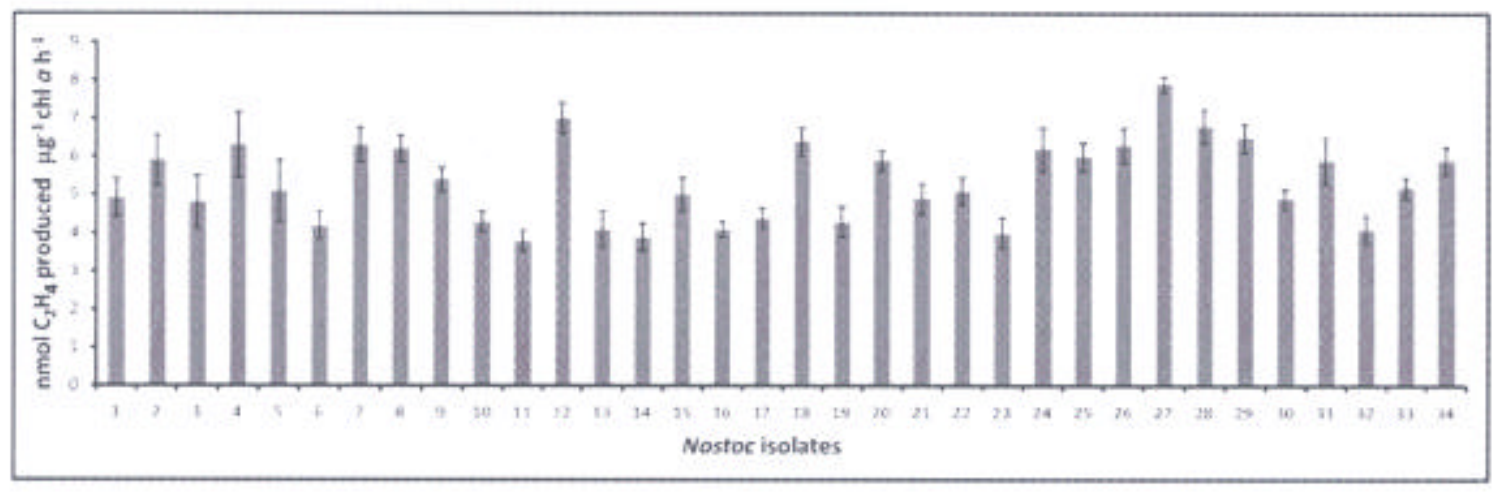

Fig. 1. (b) Nitrogenase activity of Nostoc isolates.

as Mairang, Mawphlang and Mawroh has lower $\mathrm{pH}$ (5.86.3 ) and lower temperature than warmer areas of Syntuksiar and Sung valley where $\mathrm{pH}$ was close to 7.0. The values of Shannon-Weiner's diversity, Simpson's Diversity and Simpson's Dominance indices recorded as a whole from all sites was found to be $1.630,0.68$ and 0.32 respectively. Richness was highest in Sung valley and Syntuksiar with both the sites supporting 17 strains each. Although higher diversity was seen in Sung valley, highest was recorded from Mawlai where richness was only 11 strains thereby indicating richness need not be a function of diversity in this region (Table. 3).

Nilsson et al (2002) have shown that many competent Nostoc strains colonize rice root surfaces and intercellular spaces. Such Nostoc strains were shown to have higher nitrogenase activity compared to their free-living counterparts. In pursuit of identifying indigenousNostoc strains as potential biofertilizers in acidic rice fields, we have screened our Nostoc isolates with local rice variety 'Synteng'. All 34 Nostoc isolates showed root colonization to various degrees. Isolate no.27, 12 and 28 showed high degree of colonization and enhanced nitrogenase activity (Table.4) during association. These isolates could be marked for future soil and/or seedling inoculants in acidic rice fields.

Characters like nitrogen fixation have been found to be stable under immobilization in calcium alginate beads up to a period of two years. All our purified isolates have been preserved this way after characterization and cataloguing. We believe this would be helpful in future diversity study as reference as well as in researching strains for biotechnological applications. This would greatly reduce workload such as isolation, purification and characterization of unknown strains for such study as regenerated purified cultures from the preserved beads could be the starting point for future research.

\section{ACKNOWLEDGEMENTS}

Authors would like to thank UGC, New Delhi for financial support received under Rajiv Gandhi National Fellowship and University with Potentials for Excellence scheme extended to School of Life Sciences, North Eastern Hill University, Shillong, Meghalaya.

\section{REFERENCES}

Black, C.A. (1992). Methods of soil analysis Part 1. American society of Agronomy, USA.

Desikachary, T.V. (1959). Cyanophyta. Indian Council of Agricultural Research. New Delhi, India. pp.686

Kaushik, B.D. (1994). Algalization of rice in salt-affected soils. Annual Agricultural Research, 14: 105-106.

Mackinney, G. (1941). Absorption of light by chlorophyll solutions. Journal of Biological Chemistry, 140: 315-322.

Musgrave, S.C., Kerby, N.W., Codd, G.A., and Stewart, W.D.P. (1982). Sustained ammonia production by immobilized filaments of the nitrogen fixing cyanobacteria Anabaena 27893, Biotechnology Letters, 4: 647-652. 
Myers, N., Mittermeier, R.A., Mittermeier, C. G., da Fonseca, G.A.B., and Kent, J. (2000). Biodiversity hotspots for conservation priorities. Nature, 403: 853-858.

Nilsson, M., Bhatacharaya, J., Rai, A.N., and Bergman, B. (2002). Colonization of root of rice (Oryza sativa) by symbiotic Nostoc strains. New Phytologist, 156: 517-525.

Packer, L., and Glazer, A.N. (1988). Methods in Enzymolozy. Cyanobacteria, vol. 167. Inc San Diego, California: Academic press.

Prasanna, R., Jaiswal, P., Nayak, S., Sood, A., and Kaushik, B.D. (2009). Cyanobacterial diversity in the rhizospere of rice and its ecological significance. Indian Journal of Microbiology, 49: 89-97.

Rippka, R., Dervelles, J., Water, J.B., Herdman, M., and Stanier, R.Y. (1979). Genetic assignment, strain histories and properties of pure culture of cyanobacteria. Journal of General Microbiology, 111: 1-61.

Shannon, C.E., and Weaver, W. (1949). The Mathematical Theory of Communication. Urbana: University of Illinois Press.

Simpson, E.H. (1949). Measurement of diversity. Nature, 163: 688. Singh, R.N. (1961). Role of Blue-green Algae in Nitrogen Economy of Indian Agriculture. Indian Council of Agricultural Research. New Delhi, 175.
Stewart, W.D.P., Fitzgerald, G.P., and Burris, R.H. (1967). In situ studies of nitrogen fixation using acetylene reduction technique. Proceedings of National Academy of Sciences. USA, 58: 2071-2078.

Syiem, M.B., Bhattacharjee, A., and Nongrum, N.A. (2009). Cadmium removal by an Anabaena sp. isolated from coal mining areas of Meghalaya, India. In proceedings of International seminar on Changing environmental trends and sustainable development. 129-133.

Thajuddin, N., and Subramanian, G. (2005). Cyanobacterial biodiversity and potential applications in biotechnology. Current Science, 89: 47-57.

Venkataraman, G.S. (1981). Blue-green algae: a possible remedy to nitrogen scarcity. Current Science, 50: 253-256.

Whitton, B.A., and Potts, M. (2000). Soils and rice fields. In: B.A.Whitton and M. Potts (Eds.), The ecology of cyanobacteria (pp 233-255). Dordrecht, The Netherlands: Kluwer Academic Publishers.

Wolk, C. P., (1965). Control of sporulation in a Blue Green Alga. Developmental Biology, 12: 15-35.

Wyatt, J.T., and Silvey, J.H.G. (1969). Nitrogen fixation by Gleocapsa. Science, 165(3896): 908-909. 